\title{
On the Principles for Compiling Maritime English
}

\section{Textbooks}

\author{
Gao Song and Liu Xiao-pei \\ English Department, Navigation Department, Qingdao Ocean Shipping Mariners College, Qingdao 266071, P. R. China
}

\begin{abstract}
With the development of maritime English teaching, there is a greater demand of high quality maritime English textbooks. This is a reflection of the diversification of new generation maritime English textbooks. But it also brings forth the principles for the textbook compilation. Maritime English textbook construction should adhere to the principle of the cultivation in students' listening, speaking, reading, writing and translation and incorporate the linguistic theories, teaching concepts and the understanding of classroom teaching and students' learning, so that the students will continue to improve their English levels in the process of learning the special knowledge. Therefore, the problem we faced with is to make the scientific and rational principles and compile textbooks that suit the practice of maritime English teaching and learning.
\end{abstract}

Key words: Textbook compilation, syllabus requirement, compiling principles.

\section{Introduction}

A textbook is the basic tool for the learning by the students and is the basic medium for the teaching by the teachers. Teachers, textbooks and students constitute the process of teaching activities. Researches show that, " $98 \%$ of the classroom teaching comes from textbooks instead of teachers and $90 \%$ of the assignments are completed under the guidance of the textbooks" [1]. For the use of textbooks, Cunningsworth [2] concluded as follows, (1) as the resources for written and oral materials; (2) as the resources for practice and communicative activities; (3) as the resources for grammar, vocabulary and phonetics; (4) as the origin of inspiration to activate the classroom language activities; (5) as the materials to reflect the requirements of the syllabuses; (6) as the resources for the students' autonomous learning; (7) as the support for the teachers short of confidence and experience. But a textbook is not the accumulation of static knowledge and any textbook includes at least three aspects as follows, (1) the knowledge of facts as the concepts, topics and theories to be commanded by

Corresponding author: Liu Xiao-pei, professor, research fields: maritime English, applied linguistics and translation. the students through the selection of the textbook compilers or users; (2) the competence and skills to be commanded by the students determined by the special course objectives; (3) the spiritual contents of "philosophy and sense of value carried by the foregoing requirements for knowledge and skills [3]”.

Neville Grant pointed out that, a perfect textbook is not in existence, but the most suitable textbook for the teachers and students is in existence. A textbook like this should meet the following requirements, "suiting the ability, interest and standard of the students, suiting the teaching of the teachers and suiting the teaching and examination syllabuses [4].”

Therefore, as a conception of teaching, the nature of the maritime English teaching textbooks should reflect, (1) the "course design should satisfy the special needs of the industry [5];” (2) the contents of the textbook should be closely related to special navigation science, profession and activities; (3) the textbook should lay stresses on the adaptability to the special navigational activities in the aspects of language, vocabulary, discourse and styles, etc; (4) the compilation of the textbook should reflect the theoretical background of linguistics and imply to 
adopt the teaching methods different from those for the general English; (5) the textbook should benefit the implementation of the teachers' classroom teaching and students' learning activities.

On account of the needs of teaching, scientific research and promotion of academic titles, maritime English teachers often compile the textbooks in accordance with the practical situations of teaching, while the compilation of maritime English teaching textbooks should follow certain principles. This article does not intend to dwell upon the known principles, but conduct analysis on the principles of compliance, theories, development and service.

\section{The Principle of Compliance}

The principle of compliance refers to the fact that the new textbook should come in force with the requirements of the teaching syllabus and compilers should study the teaching syllabus to be followed and put forth directive ideas so that the new textbook will abide by and achieve the objectives before it takes shape.

The teaching syllabus is a programmatic document for the description and regulation concerning the objectives, contents, requirements and evaluation, etc. of teaching, under certain teaching ideology and theory. The fabrication of the teaching syllabus collects the basic understanding of English teaching by the specialists and experts and reflects the senses of language, learning and education of the makers. Every English teaching syllabus is made and revised under the guidance of the linguistic theories and teaching methodologies in current fashion, reflects the changes of English teaching ideologies and teaching methodologies and plays a decisive role of guidance for the compilation and use of the textbooks.

Presently, there are various types of English teaching syllabuses, but they can be roughly categorized onto two basic types in accordance with their functions. One is "product-oriented syllabus" and the other is "process-oriented syllabus." The "product-oriented syllabus" mainly includes grammatical syllabus and functional-notional syllabus, while process-oriented syllabus includes procedural syllabus, task-based syllabus and content-based syllabus. The product-oriented syllabus advocates "learn and know" and requires to put the emphasis on the cultivation of language knowledge and skills, with an objective to train the students' application of the language through the command of language and grammatical knowledge. The process-oriented syllabus places its emphasis on the students' "self learning experience [6]" and requires the students to improve the language use on basis of the command of language knowledge through the application and practice of the language. Different syllabuses play important and decisive roles in "designing the teaching objectives, teaching objects and teaching methodologies set by different textbooks [7]." Those textbooks aiming at the command of language knowledge and language skills can not adopt the task-based teaching syllabuses as the guidelines for macro design of textbook compilation and teaching implementation, because the textbook like this requires that the focus of teaching be placed on the transmission of language knowledge and development of language skills and its teaching means is to stress on reading and writing and the accuracy of language use as its ultimate goals through the forms of the exercises of sentence patterns, use of grammar and practice of language and therefore, the textbook regards the knowledge of phonetics and grammar, reading and writing as the center and the teaching method is mainly grammar translation.

Therefore, the traditional viewpoint is, the Product-oriented teaching syllabus is used in the teaching of general English and the Process-oriented teaching syllabus is used in the teaching of special English. The idea that the authors of this article hold is, we use Product-oriented syllabus in the initial stage of maritime English teaching, to teach the phonetics, vocabulary, grammar knowledge and train the 
language skills to enlarge the vocabulary, increase the reading ability and improve the expression of the students, and we use the Process-oriented syllabus in the maturity stage so that the students acquire the maritime knowledge by using the target language. In order that the textbook adequately reflects the guidance of the teaching syllabuses, the compilers should be clear in mind that, what kind of a teaching syllabus is to be followed in compiling the textbook? What kind of investigation has been made? What kind of need is to satisfy? What kind of a purpose is to achieve? A textbook like this will not betray the root purpose of the compilation.

\section{The Principle of Theory}

The principle of theory refers that, the textbook should reflect the basic understanding and attitude of the compilers in the process of compiling and the textbook should bring the basis of language theories and suitable ideology of teaching methodology. Linguistics and the teaching methodologies rooted herein have gone through historical development and proof and the authors will make discussions in three aspects categorizing the linguistic theories and teaching methodologies in accordance with their development histories and usable environments.

\subsection{Traditional Linguistics and Grammar Translation Methodology}

Traditional linguistics came into being in the process of the description of languages in Latin and Greek two thousand years ago. Plato recorded in detail the arbitrary nature of vocabulary in his book "Cratylus", and has been used until today in explaining the connection between vocabulary and material. Ancient Indian linguist Barney distinguished the parts of speech and located eight forms of verbs [8] in his book "Sanskrit Grammar." As an initial product of linguistics, the traditional linguistics stresses on the correctness of language.

The grammar translation methodology originated from the traditional linguistics was boomed in the Middle Ages when Europeans were learning the ancient Latin language. On account that the Latin language had a rigor and logical grammar system, it was regarded as a good means in training the ability of reasoning, observation, comparison and integration. It has two important characteristics, emphasis on the development of reading ability and the application of grammar teaching. As a result, the most direct definition of the grammar translation methodology is, a teaching method using the mother tongue in teaching with translation and grammar learning as the center. It is characterized in, (1) conducting further analysis and studies on the target language and its grammatical structures, stressing on the systematic teaching of vocabulary and grammar knowledge; (2) having a complete and systematic set of grammar and grammar is the focus of teaching; (3) stressing on the ability of mother tongue and translation, with large amount of translation exercises in the processing of teaching and the examination contains translation from mother tongue to the target language and vice versa; (4) stressing on reading and writing and neglecting listening and speaking; (5) stressing on the accuracy of language with the texts as the materials for grammatical analysis and the mother tongue as the teaching language.

American applied linguistic expert H. D. Brown says, in the teaching using the grammar translation methodology, the fine grammar rules and extensive vocabulary knowledge make language input easier for understanding, systemizing the various language phenomena for the foreign language learners who will be able to conduct stage treatment[9] of the language from the elementary to the profound. The grammar translation methodology helps the students to ascertain or negate their intentional or unintentional hypothesis of the target language and distinguish the similarities and differences between the mother tongue and target language and helps them to internalize the structures of the target language so as to improve the 
expression abilities.

The compilation of maritime English textbooks in the initial stage should reflect the characteristics of the traditional linguistics and preinstall the application of the grammar translation teaching methodology so that the students will accurately cognize and memorize in detail the special vocabulary, sentence structure, discourse form, grammatical core, definition and legal provisions, etc., which is profitable for the students to lay a solid foundation and improve in proper sequence for the learning of maritime English of a higher level.

\subsection{Structural Linguistics and the Audio-lingual} Method

The structural linguistics came into being in the 20th century and it has the following theoretical characteristics, oral language is prior to written form; grammar is a description instead of regulations.

The textbooks of structural linguistics are chosen in accordance with grammatical patterns and structures. On account that structuralism places stress on the priority of oral English in describing the language phenomena, it naturally calls for the priority of listening and speaking in language teaching and hence the existence of “audio-lingual method." The structural linguistics divides the language into the units of phonetics, vocabulary and sentence, etc., and the language skills are also categorized into listening, speaking, reading, writing and translation. Therefore, the learning of a language means the command of the basic language units and their combination rules from phonemes to sentences and language teaching becomes the process in which the teacher conducts sonic stimulation and students react to the stimulation.

The audio-lingual method originated from the series of theories is guided by the form of the language and esteems that language teaching should be focused on the form and structure and that the ultimate purpose of learning is the command of the language structure. Its method is sentence patterns exercise, that is, stimulation and practice. The audio-lingual method holds that, the sentence pattern is the typical sentence model and the basic structure of a language and it not only carries the meaning of structure, but also that of vocabulary and social culture, it is the core of language teaching. The teaching model based on the audio-lingual method can thus be summarized as the mechanical exercise and recitation and understandable exercise and practice. This repetition and mechanical sentence pattern exercise play an important role in the students' command of the basic language expression.

The characteristics of the audio-lingual method of the structuralism include, (1) the language teaching follows the order of listening, speaking, reading and wiring, with the priority in listening and speaking supplemented by reading and writing; (2) the exercise of sentence patterns is the basis of language teaching and all the teaching activities will be organized round the sentence patterns; (3) the process of language teaching is one to form the language habits through “stimulation and reaction” and teaching should stress on the imitation, exercise, memory and repetition; (4) the purpose of language teaching is to train the language ability instead of language knowledge; (5) the teaching of a language should make use of the visual aids and language situations and use the target language.

In comparison with grammar translation method, the audio-lingual method places stress on the priority of listening and speaking, and emphasizes the training and cultivation of language skills. Most maritime institutions put forth the teaching principles of "priority of listening and speaking, supplemented by reading and writing” on basis of this. It divides the language system into various levels, for the convenience of the command by the students; the priority of listening and speaking draws the attention of the oral communication and solves the problems as “dumb English”; the repeated learning and exercises internalize the knowledge learned by the students until the point of skillful use; the stress on the exercise of sentence patterns is based on vocabulary, benefiting 
the learning of the students; the comparison and analysis of language help the students to better understand the structure of the language and form the habit of language use and the application of modern scientific and technological techniques create a favored atmosphere for the students. Therefore, those textbooks using the audio-lingual method as "English 900" received wide welcome home and abroad. The crash courses based on "stimulation and reaction" theories in the initial stage of the opening and reform had provided effective guarantee for the international communication of the research and technical staff.

It is natural for the laddered development for the students to achieve progress in language learning to go through output on basis of input, fluency on basis of accuracy and the application of audio-lingual method of structuralism on basis of grammar translation of the traditional linguistics. Although the teaching contents of maritime English reflect the characteristics of technical terms and special structures yet with the improvement of the students' language ability and the need of communication in special English, the textbooks ought to bring the spirit of structural linguistics to make the students command the special terms, structures and expressions of maritime English in the process of repeated learning and exercises. The "SMCP" and "Sea Speak" are very good learning materials and should be brought into the maritime English textbooks. For the students of intermediate level, teachers should more frequently use the audio-lingual method so that the students learn and know the linguistic characteristics of maritime English in the process of language exercise to improve their application of the language.

\subsection{Sociolinguistics and Communicative Method}

Sociolinguistics makes studies into the relationship between language and the society and observes the language from the angles of various social sciences (such as sociology, anthropology, ethnology, psychology, geography and history, etc. [10]). It regards the language as a social phenomenon and advocates putting the language in the social backgrounds hence the birth and use of the language for study and observation.

Sociolinguistics breaks the tradition of the stress on the language forms in the world of linguistics and provides a wider expectation for language studies and teaching. It holds that, there should be a central purpose of language teaching, to train the students what to say, what not to say, when to say and how to say, to train the students to master the "rules of speaking” with the purpose to let the students to make correct reactions in specific language situations. Hence a new teaching method, communicative method, came into being. The teaching with the communicative method breaks the traditional teaching model in which the teacher teaches and the student learns and is evolved into a communication between the teachers and students and the effect of teaching is no longer determined by the teaching and learning but the interaction between teaching and learning. The focal point of the communicative method is not how much knowledge the students command in the aspects of phonetic and grammatical knowledge, but putting the students in the actual communication to gain the experience in the process of communication and improve their ability in language application.

The communicative method originated from the sociolinguistics stresses on the ability of communication and treats the cultivation of the students' communicative ability as the final goal; it stresses on the social culture and believes that language is a part of the special culture and that teaching of the communicative principles should be conducted in combination with the elements of social culture to train the acceptability and communicability of the students' use of the language; it stresses on the discourse teaching and the language unit it cares is no longer the grammatical unit of the language but the communicative unit of the language and therefore holds that language teaching should be conducted in 
the level of discourse; it stresses on situational teaching, as Halliday has pointed out that, "a discourse functions in a certain situation and some features can be subtracted in relation to description and analysis[11].” The language situation and the use of a language are inter-dependent, on the one hand, successful communication depends on the choice of language in consideration of the influence of situation and on the other hand, the choice of language is influencing the construction of the situation. In the choice of language, situation and language structure interacts to produce the meaning of speeches. Its core of application is, language teaching should be started from the authentic situation, with the situation as the presupposition of existence and students as the center to solve the problem of "pragmatic failures" and help the students construct the language communicative abilities needed for future life and work. Many maritime English teachers simulate the communicative situations in the process of teaching to conduct onsite teaching and emphasize the function of cross-culture communication. It is because they have found the root of the communicative difficulties of the students.

Presently for students of higher level, the problem is not that he cannot listen or speak, but whether he knows how to speak. The unnatural and out-of-situation language learning and exercise make it hard for the students to get into the actual situation. Therefore, the communicative teaching method based on sociolinguistics is a step forward on the fundament of grammar translation and audio-lingual methods. Under the guidance of the theory and practice, it is necessary to realize that, out of its special situation of application, the compiling of the maritime English textbooks should take into adequate considerations to provide authentic situations for language application and the practice of teaching should be put into the process of realistic production to produce authentic or simulated communication, so that the knowledge and skills acquired will meet and apply the practicality of the shipping industry.

\section{The Principle of Development}

It should be clarified that, in the process of language teaching, the textbook is not the ultimate medium and the teachers' further development of the textbook is of greater importance. Therefore, when compiling the textbook, the compilers should leave room for the further development. The compilers should provide adequate oral and written experience of language and put the students into the abundant, meaningful and understandable language input so that they are able to cope with various topics, themes and incidents in various discourse types; provide authentic language input which should be typical of routine life and work, otherwise they will not acquire the effective ability in using the language; provide situational input, because the students need various experiences of language use to serve the various purposes of communication and the out-of-situation input will not contain adequate information on the user, communicator, purpose and effect; provide adequate language samples in practical use so as to give the students the natural and circulated language units or language characteristics profitable for natural acquisition.

To ensure that the students will have a good command of the language in use, to integrate the active thinking to the process of language learning experience for the acquisition of the deep level information processing [12] necessary for effective and long lasting learning and to benefit the students to transfer the high level skills to the use of language, such as forecasting, establishing connection, interpretation and assessment [13], etc., it is necessary to motivate the students to invest their cognition and emotion to the leading position of the textbook to ensure their participation in learning; to make use of the learning activities to induce the students to render active thinking on the language materials they are learning to ensure the autonomous ponderation and to 
take advantage of the learning procedures for the students to appreciate the language when using it in communicative activities to ensure the emotion in the process of learning.

The textbook should enable the students to benefit from their mental resources in acquiring and using the language and the consequence will be more satisfactory if they can construct multidimensional representation from the language they experience and that they are going to produce. For example, in the process of learning and using a language, the students tend to use the emotional reaction as mental imagination and self talk to construct connections with their actual life, evaluation, prediction and personal viewpoints, etc. The organic connection with the language they are experiencing and using will enhance the long-term learning with more splendid forms and transfer it from learning to practical use, develop the ability in using the language to cope with various situations and purposes and gain the self esteem that they have only in using their mother tongue. The textbooks should contain rich learning activities to encourage the students to produce mental imagination and self talk in experiencing the language materials and help the students to conduct introspections on their mental activities in the process of completing their learning tasks so as to more frequently use their mental strategies in similar activities.

On account that maritime English carries features that are different from others, if then the students can actively notice the use of the language items or features, they tend to acquire the sense of the target language and feel easier to learn the language. Especially, when they invest adequately in cognition and emotion, they will get to better results with this active attention. They will be more likely to look back to the use of maritime English and better notice the use of the language items and similar features so as to improve the ultimate effect of their learning. As a result, the compilers should note, (1) to implement the experiential teaching in the form of autonomous learning to let the students overall experience the language, practice the implicit learning with attention to the language features in re-experiencing the language use to produce explicit learning; (2) to help the students to actively find out the features of maritime English in the form of cooperative learning, which is more effective than reminding them with clarified explanation or illustration; (3) to help the students to develop the learning abilities in the form of research learning and if the students can implement initial researches into the materials provided by the teacher and textbooks and if the textbooks will provide room for research learning, the students will better command the learning materials. The three methods also coincidentally reflect the characteristics of "teaching-learning-doing" of vocational maritime English education.

\section{The Principle of Service}

\subsection{Serve the Learning of the Students}

Whether the selection is favored by the students and whether they will arouse the learning interest of the students are critical for the success of a textbook. Widdowson pointed out that, effective language teaching should be in compliance with but not in opposition to the natural process. It should accelerate but not hinder the learning progress. The teacher and teaching should suit the students [14]. The textbook should provide motivation for the students, taking into considerations the demand of learning and active participation in classroom activities and providing assistance for their learning procedure but not an inflexible method forced on them. Maritime is a continuous process, moving from familiar language items towards the difficult and the qualities of improvement in proper sequence, clarification, laddered progress, acceptability of the teaching methods, interest of the topics under discussion, quality and quantity of exercises, etc. should be taken into consideration. The textbook should provide multiplied learning methods and strategies for the 
choice of the students who will then gradually form their own learning style and strategies. A good textbook should encourage the students to form their own methods and manners with the functions of motivating them, satisfying their expectations, stimulating their investment, organizing and cultivating and consolidating their studies.

\subsection{Serve the Teaching of the Teachers}

In all the teaching environments, the teacher's role calls for careful considerations, because he is the director for students' learning and deciding person of the value of a textbook. If the compilers fail to take into consideration the diversity of a teacher, the textbook will lose its function in improving teaching. A teacher, like the students, is characterized in diversity. A textbook should provide adequate and suitable guiding materials to give prominence of each teacher's privileges, such as the various educational backgrounds, professional experience and teaching ideology [15], etc.

The course plan and compendium are by no means immutable and frozen and they should suit the situation of implementation, which is the consequence of the interaction between the planner and implementer and its critical point lies in adjustment. In the process of implementation, teachers should conduct adjustment and reformation to the course contents and structures in accordance with the practical situation and their understanding of the course and they should treat the textbook as the course book for interpretation, emphasize the cooperative research and stress on the interaction between teacher and students and the course book. Therefore, teachers should use flexible teaching methods, and the teaching itself should contain the innovation to bring into the classroom "those that cannot be incorporated into the textbook but suit the knowledge acquisition by the students." The textbook should give its place to the subjectivity of the teachers and students and teachers should make flexible use of the textbook to arouse the initiatives and to benefit the overall development of the students. A textbook is an effective tool for the practice of teaching and is the important basis for the teaching content. Good language textbooks should be properly used by the students at various levels and provide space for the innovative use by the teachers.

\subsection{Serve the Teaching Methods}

Cunningsworth [2] believes that, "one of the functions of the textbook is to present the students with the language items in the most effective and prompt manner and this means that the compilers need to have their own viewpoints concerning how a language is learned and taught", "the organizing manner of the language contents and type of the classroom activities will produce profound influence on the process of learning”. The teaching methods are on the change, because they should serve the learning of the specific teaching purposes and the limitations include the teaching contents, students' psychological situations, teachers' qualifications and teaching conditions, etc. When choosing the teaching methods, the teachers first of all are faced with the contents of presentation, and then the acceptability of the students, the professional level of themselves, the present teaching conditions and the teaching methods on analysis and integrated considerations.

\section{Conclusion}

The compiling of a maritime English textbook is the piling of the language materials and is not the reflection of profitability. It is the consequence of the efforts of the compilers, like a piece of artistic work. Everything, from the investigation and analysis, planning and writing to designing and scheming, implementation and taking shape, should demonstrate the understanding and operation of the target language, familiarization and appreciation of the shipping industry, the comprehension and prediction of the students and brings forth the known and innovative principles into the final products, making 
the textbook a flexible assistance for the teachers and valuable resources for the students.

\section{Acknowledgements}

This paper is funded by the project, "Development of Maritime Audio-Video English Textbooks Based on Shipping Production and Operation," China Ocean Shipping (Group) Company. Project Code, 2013-1-H-008.

\section{References}

[1] Suarz, E. T. A. 2001. "Behavioral Systems Analysis of Textbook Quality Improvement.” Doctoral dissertation, Western Michigan University.

[2] Cunningsworth, A. 2002. Choosing Your Course-book. Shanghai: Shanghai Foreign Language Education Press.

[3] Grant, N. 1987 Making the Most of Your Textbooks. New York: Longman Group UK Limited.

[4] Li, X. 2008. “'Teaching Textbooks' or 'Using Textbook': A Perspective of Improving Teaching Materials Function.” Research of Educational Development 10.

[5] Dudley-Evens, T., and St. John, M. J. 1998. Development in English for Specific Purposes.
Cambridge: Cambridge University Press.

[6] Nunan, D. 1988. Task-based Syllabus Design: Selecting, Grading and Sequencing Tasks. Cleveland, UK.

[7] Diamond, R. M. 1998. Designing and Assessing Courses and Curricula: A Practical Guide. San Francisco: Jossey-Bass.

[8] Xu Z. M. 2013. Brief History of European and American Linguistics. Shanghai: Fudan University Press.

[9] Brown, H. D. 2002. Vision of Western Applied Linguistics. World Books Publishing Company.

[10] China Encyclopedia, 1998 "Language and Literature”

[11] Halliday, M. A. K. 2008. An Introduction to Functional Grammar. Beijing: Foreign Language and Teaching Research Press

[12] Craik, F. I. M., and Lockhart, R. S. 1972. "Levels of Processing: a Framework for Memory Research.” Journal of Verbal Learning and Verbal Behavior.

[13] Tomlinson, B. 1998. Materials Development in Language Teaching. Cambridge: Cambridge University Press.

[14] Widdowson, H. G. 1996. Teaching Language as a Communication. London: Oxford University Press.

[15] Williams, D. 1983. "Developing Criteria for Textbook Evaluation.” ELT Journal. 